http://dx.doi.org/10.35381/racji.v5i1.621

\title{
El alcance de la responsabilidad extracontractual del Estado por sentencia condenatoria reformada o revocada
}

The scope of the non contractual liability of the State for reformed or revoked guilty verdict

\author{
Jorge Adrián Vásquez-Ayerve \\ jorge.vasquez@psg.ucacue.edu.ec \\ Universidad Católica de Cuenca, Cuenca \\ Ecuador \\ https://orcid.org/0000-0003-3589-1723 \\ Cecilia Ivonne Narváez-Zurita \\ inarvaez@ucacue.edu.ec \\ Universidad Católica de Cuenca, Cuenca \\ Ecuador \\ https://orcid.org/0000-0002-7437-9880 \\ Enrique Eugenio Pozo-Cabrera \\ epozo@ucacue.edu.ec \\ Universidad Católica de Cuenca, Cuenca \\ Ecuador \\ https://orcid.org/0000-0003-4980-6403 \\ Juan Carlos Erazo-Álvarez \\ jcerazo@ucacue.edu.ec \\ Universidad Católica de Cuenca, Cuenca \\ Ecuador \\ https://orcid.org/0000-0001-6480-2270
}

Recibido: 14 de noviembre de 2019

Aprobado: 15 de diciembre de 2019 


\section{RESUMEN}

Dentro de la nueva realidad Constitucional se considera al ser humano como el centro los derechos, siendo se analiza la responsabilidad extracontractual del Estado, generada por su incorrecto accionar en el ámbito judicial y las consecuencias dañosas e ilícitas que esto genera, derivando todas en la obligación de repararlas de forma integral. Esto haciendo énfasis, en aquellos procesos penales en que alguien se haya visto privado de su libertad de forma injusta. Para esto se ha empleado una metodología analítico - sintética. Se ha escogido este tema para determinar la real existencia de obligación preparatoria en casos como el indicado, es necesario efectuar un completo estudio de cada proceso a fin de determinar si el hecho dañoso es imputable al Estado, en la forma en que se encuentra redactada la Norma Constitucional del Ecuador puede llevar al falso convencimiento de que en todo caso procede la reparación.

Descriptores: Responsabilidad estatal; daño; reparación; error judicial; recurso de revisión.

\section{ABSTRACT}

Within the new Constitutional reality, the human being is considered as the center of rights, being analyzed the extra-contractual responsibility of the State, generated by its incorrect actions in the judicial field and the harmful and illicit consequences that this generates, deriving all in the obligation of repairing them in an integral way. This emphasizing, in those criminal proceedings in which someone has been unjustly deprived of his freedom. For this, an analytical - synthetic methodology has been used. This topic has been chosen to determine the real existence of a preparatory obligation in cases such as the one indicated, it is necessary to carry out a complete study of each process in order to determine if the harmful fact is attributable to the State, in the way in which the Constitutional Rule of Ecuador can lead to the false conviction that in any case the repair proceeds.

Descriptors: State responsibility; damage; reparation, judicial error, appeal of revision.

\section{INTRODUCCIÓN}

Se suele decir que el Derecho y la política se encuentran interrelacionados de forma bilateral, por cuanto el primero impone límites a la actividad política, y esta a su vez tiene el poder para modificar al Derecho, es así, que quien detenta el poder, producto 
de la actividad política, tiende a delimitar la norma mediante el instrumento llamado Constitución, siendo por tal motivo la misma un documento de naturaleza política, en donde se plasma el proyecto bajo el cual se esquematiza el modelo de gobierno a seguir, en este sentido, el Derecho Constitucional nace con el fin de encargarse del estudio no solo de la estructura misma del Estado, sino también de los parámetros bajo los que actuarán sus órganos integrantes, de la organización del poder político y sobre todo del proyecto plasmado en la Constitución. (Ramallo, 1982; Oyarte, 2019).

En la Carta Magna del Ecuador, se establece una particular división de poderes siendo los mismos el Ejecutivo, Legislativo, Judicial, Electoral y el de Participación Ciudadana y Control Social, de igual manera se reconoce la obligación del Estado por las actuaciones emanadas de sus agentes (Jiménez, 2013), por tanto, al ser el Poder Judicial parte integrante del Estado, no pueden sus actos abstraerse de esta realidad, es así que, cuando alguien considera que se ha visto afectado por alguna sentencia injusta, por la cual ha sido privado de su libertad, le asiste el derecho a reclamar en vía judicial el resarcimiento por el daño causado, conforme se puede apreciar en el inciso final del artículo 11.9 de la norma fundamental ecuatoriana, que señala

Cuando una sentencia condenatoria sea reformada o revocada, el Estado reparará a la persona que haya sufrido pena como resultado de tal sentencia y, declarada la responsabilidad por tales actos de servidoras o servidores públicos, administrativos o judiciales, se repetirá en contra de ellos. (Asamblea Nacional Constituyente, 2008, p. 12).

En consecuencia, es necesario tener claro que la administración de justicia, al ser parte integrante del Estado, tiene responsabilidad por los actos de ella emanados, es por esto imperativo que en todo juicio se observe el debido proceso, garantizando de esta forma la tutela judicial efectiva, con lo cual se estará en un escenario de respeto a los derechos y correcta aplicación de justicia (Sentencia C-341/14, 2014), por lo tanto, la Constitución ecuatoriana reconoce la obligación de resarcimiento en los casos en que la administración de justicia no haya respetado el debido proceso, dando una respuesta imperfecta, más para efectos del presente estudio interesan aquellos casos señalados 
en líneas anteriores, en los que de la lectura de la norma se puede considerar que la sentencia condenatoria constantemente ha sido injusta por deficiencias en la sustanciación del proceso.

Sin embargo, esto no siempre es cierto, por su propia naturaleza en el recurso de revisión son presentados nuevos elementos que no fueron de conocimiento de quien dictó la sentencia condenatoria y que incluso podrían haber sido deliberadamente ocultados, debiendo analizarse si el daño se ha generado en un accionar ilegítimo de la juzgadora o juzgador (Fundación Regional de Asesoría en Derechos Humanos INREDH; Centro Ecuatoriano para la Promoción y Acción de la Mujer CEPAM, 2000), surge de esta manera el problema de establecer los parámetros legales bajo los que una sentencia revocada merece una indemnización por parte del Estado.

En esta perspectiva, el objetivo del artículo consiste en establecer cuál es el origen y alcance de la responsabilidad del Estado, en lo referente al último inciso del artículo 11 numeral 9 de la Constitución, recogido en el artículo 32 del Código Orgánico de la Función Judicial, puesto que la norma en la forma en que está redactada lleva a entender que hay responsabilidad del Estado, en todo caso y sin excepción, siempre que haya una sentencia condenatoria reformada o revocada, no obstante, se considera que para el efecto habría que analizar en cada caso puntual si ha habido alguna conducta antijurídica por parte del órgano jurisdiccional, que haya a su vez llevado al cometimiento de una injusticia y causado un daño (Hernández, 2017).

\section{DESARROLLO}

\section{Origen de la responsabilidad estatal por actos emanados de sus agentes}

Antes del surgimiento del Estado, organizado como hoy se lo conoce, el modelo de gobierno más extendido eran las monarquías absolutas, las mismas que tenían soporte en el poder divino del rey, otorgado de forma directa por Dios para gobernar a los hombres, razón por la cual ninguno de los actos del soberano podía tan siquiera ser cuestionado como erróneo, teniendo un poder ilimitado, de ahí aquella expresión 
anglosajona the king can do no wrong (Gordillo, 2017), que pone de manifiesto la nula responsabilidad por parte del gobernante y por extensión de sus agentes respecto de sus actos. En esta época el poder era repartido entre el soberano y la iglesia, particular que se aprecia de la carta de Gelasio I, dirigida a Anastasio; y, aunque nunca se utiliza esta expresión, aparece la denominada doctrina de las dos espadas, en la que iglesia y Estado son dos manifestaciones de poder divino, siendo a su vez interdependientes para mantener el poder cada uno (Mir y Dalcero, 2007).

Se puede apreciar que en esta época la influencia de un poder celestial sobre la organización misma de los Estados era muy profunda. Incluso tomando en cuenta la realidad ecuatoriana, recién con la revolución liberal hubo una separación real entre Estado e iglesia, pese a lo cual esta última en la actualidad, sigue teniendo gran influencia dentro de las actividades diarias tanto de particulares como en el sector público (Mogrovejo, 2009).

En la modernidad se empezó a reconocer que los actos u omisiones el Estado, causantes de algún perjuicio, implicaban a su vez la obligación de resarcir a las víctimas. Esto ocurrió, en la medida de que la tesis de la autoridad otorgada por Dios, fue superada, reconociéndose que el poder reside en el pueblo, siendo este el verdadero soberano, debiendo el gobernante enmarcar sus actuaciones en el respeto de los derechos y lo prescrito en la ley (Jiménez, 2013), esto sin embargo, fue un proceso lento, ya que inicialmente no se quiso aceptar que quienes detentaban el poder fueran totalmente responsables, esta vez ya no por mandato divino, sino en razón de que al ser dado el poder por el pueblo no podían ser fiscalizados sus actos.

Más adelante se tiene que uno de los puntos de inflexión en el reconocimiento total del Estado como responsable por los actos emanados de él o sus agentes, es el denominado Fallo Blanco, emitido por el Tribunal de Conflictos de Francia el 08 de febrero del año 1873, mediante el que se declaró la responsabilidad del Estado por la amputación de una pierna que sufrió la hija del señor Juan Blanco, al ser víctima de un descuido en el cumplimiento de sus labores por parte de agentes estatales, fue este el 
primer caso en que se estableció una separación entre la responsabilidad establecida en el derecho civil y la del Estado (Romero, 2015). De manera adicional se debe anotar que este fallo sentó las bases del derecho administrativo.

De lo expuesto se concluye que, dentro de la evolución de la responsabilidad estatal, se evidencian tres distintos estadios: un primero, en que el Estado tiene autoridad sin límites para gobernar, sin derecho alguno de reclamo de los particulares por los daños causados por el regente, en que las personas son consideradas cosas; ha sido llamado por varios autores como Estado de Policía. Un segundo, que tiene su origen en la Revolución Francesa, momento histórico en el que se reconoce a los individuos como sujetos de derechos, con lo que además desaparece aquella concepción de Estado monárquico absolutista, pese a esto la responsabilidad y obligación de resarcimiento por daños causados se encuentra en incipiente estado, habiendo más que nada un reconocimiento de responsabilidad por parte de agentes estatales. Un tercero, que se puede llamar Estado moderno, en el que cada vez se reconoce con mayor amplitud la responsabilidad, ya no solo de sus agentes sino del gobierno mismo, incluso respecto de aquellos actos en los que no hay culpa en el accionar (Gordillo, 2017).

En el caso del Ecuador en la Constitución del año 1998 en sus artículos 20, 21 y 22, ya se reconocía la responsabilidad del Estado, delegatarios y concesionarios de indemnizar aquellos perjuicios causados en la prestación de los servicios. De igual manera en la Constitución del año 2008, el Constituyente reafirmó la responsabilidad del Estado por sus actos, siendo reconocida en el artículo 11 numeral 9, lo cual ha sido observado por la Asamblea Nacional en el Código Orgánico de la Función Judicial en el artículo 32 en el que se determina la responsabilidad estatal por el mal funcionamiento en la administración de justicia, haciendo énfasis en aquellos casos en que haya habido privación de la libertad. Es ampliamente aceptado que la Constitución ecuatoriana es muy avanzada en cuanto al reconocimiento de los derechos, incluso se efectúa un reconocimiento expreso de que las obligaciones estatales surgen no solo de sí mismo sino también de las acciones u omisiones de sus agentes. 
En este marco de referencia, la responsabilidad de reparación por el daño causado puede tener dos distintos tipos de origen, contractual si se basa en la preexistencia de algún convenio o contrato, mediante el que las partes intervinientes establecen determinada obligación, a la que no se ha dado cumplimiento; y, extracontractual cuando de forma previa no existe vínculo contractual, generándose este caso cuando es proferido un daño a una persona, siendo indistinto que este accionar sea culposo o doloso (Scognamiglio, 2001, Corte Nacional de Justicia, 2009). Esta clasificación de la responsabilidad en contractual y extracontractual es aplicable tanto para las relaciones entre particulares, como también entre ellos y Estado.

En cuanto a la responsabilidad extracontractual del Estado, de la lectura del artículo 11.9 de la Constitución (2008), se evidencia que esta puede darse en el ámbito de la actividad administrativa, por falta o deficiente prestación de servicios públicos, no solo de los funcionarios o funcionarias, sino también de que quienes actúan en razón de una delegación o concesión; de otro lado ésta responsabilidad también se puede dar en el ámbito de la actividad judicial por detención arbitraria, error judicial, retardo injustificado, violación del derecho a la tutela judicial efectiva, violación de principios del debido proceso y por sentencia condenatoria reformada o revocada (Moreno, 2016). Con respecto a la responsabilidad extracontractual del Estado en cuanto a la actividad judicial, se desprende que esta puede ser darse en cualquier rama del Derecho, haciendo énfasis en el área penal, que es la única en que puede haber sentencias condenatorias.

Tomando en cuenta que, en la Constitución del año 1998, ya se hacía un reconocimiento de responsabilidad estatal por errores cometidos en el cumplimiento de la actividad judicial, la ex Corte Nacional de Justicia (Corte Suprema de Justicia, 2002), indicó que para que se pueda considerar la existencia de error judicial no basta la sola revocatoria de disposiciones judiciales, sino que es necesario que haya un error grave, incontestable, manifiesto, de hecho o de derecho, en el que se haya ignorado de 
manera total la normativa jurídica aplicable, siendo esto obvio, para cualquiera y no solo para la parte perjudicada (Granda Torres \& Herrera Abrahan, 2019).

El Código Orgánico de la Función Judicial (2009) en su artículo 32, de forma concordante con el artículo 11.9 de la Constitución, consagra la obligación estatal de reparación en cuanto a la inadecuada administración de justicia, ampliando el rango de protección a los casos de prisión preventiva arbitraria o donde de forma posterior hubiere sobreseimiento o absolución, cabe anotar que ya no se habla solo de una indemnización, sino de reparación siendo este un concepto más amplio que ya no implica solo el aspecto económico.

\section{El daño ilegítimo y la reparación integral como parte fundamental del proceso}

El daño es todo aquello que causa un dolor o padecimiento físico, moral o patrimonial, producido por terceros, fenómenos provenientes de la naturaleza, hasta por uno mismo, dañoso, culposo o fortuito, e incluso puede originarse en una causa lícita o ilícita. Respecto a estas últimas dos categorías, aunque parezca confuso que se origine en una causa lícita, un ejemplo de daño lícito es aquel causado a quien pierde un concurso o competencia, es innegable que se ha causado un padecimiento, sin embargo, el mismo no será indemnizable, ni tiene efectos jurídicos (Naveira, 2004), para fines de este artículo es necesario analizar el daño que genera efectos jurídicos, que es el ilícito o antijurídico, causado a alguien que no ha ejecutado ningún acto u omisión, por lo que no tiene el deber de soportarlo (Corte Constitucional de la República de Colombia, 1996).

La principal labor de la Función Judicial, es la de administrar justicia, es decir, sustanciar los litigios legales, que en su gran mayoría son de naturaleza adversarial, con intereses contrapuestos, siendo así, la juzgadora o juzgador al momento de emitir su sentencia dará la razón a uno u otro, por tanto, la sentencia dictada será perjudicial para alguien, siendo este un claro ejemplo de un daño lícito. Pese a lo expuesto, habrá casos en que se esté frente a una sentencia judicial que cause un daño ilícito, por 
originarse de un proceso viciado de nulidad o por no cumplir con el requisito de motivación, el cual se verifica mediante el test de motivación que impone a toda resolución ser dictada dentro de los parámetros de razonabilidad, lógica y comprensibilidad (Corte Constitucional del Ecuador, 2012).

El artículo 11.9 de la Constitución (2008), utiliza expresiones como daño producido o pena, refiriéndose esta última de manera específica al proceso judicial penal, en concordancia con el precepto constitucional señalado, el artículo 229 del Código Civil Ecuatoriano (2005), deja sentado que para que el daño sea reparable debe ser imputable a la malicia o negligencia de quien lo causa. Al hablar de malicia se está ante un acto doloso, que para ser considerado como tal debe reunir dos elementos: ser efectuado por alguien consciente de lo que realiza y actuar con plena voluntad de causar el daño.

Por otro lado, la negligencia supone el no tomar todas las previsiones necesarias para evitar que se cause un daño, se podría decir que se actúa con ligereza (Velásquez y Gutiérrez, 2011). Para que el daño pueda ser considerado dentro del aspecto jurídico, Naveira (2014), señala que deben ocurrir ciertas circunstancias:

1) Que el daño lesione un interés humano; 2) que el hecho dañoso sea imputable a una persona distinta del titular del interés lesionado; 3) que el daño pueda calificarse como antijurídico, por haber recaído sobre un interés que el Ordenamiento considere digno de protección o de tutela jurídica; 4) que el daño sea cierto, tanto en su existencia como en su cuantía y 5) que el daño resulte probado por quien lo alega. (p. 15)

Debe ser considerado que no todo perjuicio causado al usuario de la administración de justicia se constituye en un daño indemnizable, puesto que para que esto ocurra debe necesariamente haber alguna deficiencia en la administración de justicia, Hernández (2017) afirma que para que proceda una reparación por un daño causado, el mismo debe ser ilegítimo o antijurídico, o lo que es lo mismo injusto, debiendo indicar que esto no solo se da en las relaciones entre Estado y administrado, sino también en las relaciones entre particulares. 
El reconocimiento de responsabilidad por el daño ilícito causado, conlleva la obligación de reparación o satisfacción, que no es sino tratar de volver al estado previo al daño causado, lo cual no en siempre será posible, debiendo en estos casos buscarse una forma de reparación adecuada (Nanclares y Gómez, 2017). En este contexto; y, tomando en cuenta que el Ecuador es un Estado de Derechos y justicia, el resarcimiento debe ser integral por lo que no se agota en una indemnización económica, constituyéndose la reparación por sí misma en un derecho constitucional (Sentencia 004-13-SAN-CC, 2013). Tanta relevancia tiene la reparación por el daño causado, que en la actualidad no se discute que el proceso finaliza con el cumplimiento de la misma (Sentencia 0004-09-SIS-CC, 2009). En este contexto, dentro de todo proceso en que se establezcan responsabilidades, la reparación tiene suma importancia, para el restablecimiento de la dignidad del afectado, en virtud de esto al momento de ser emitida deberá considerarse a la persona de forma integral (024-14SIS-CC, 2014).

Al hablar de restitución integral, se dice que abarca distintos aspectos del resarcimiento, más allá del económico; se puede clasificar a las medidas de reparación, restitutio in integrum, medidas de rehabilitación, compensación, satisfacción; y, garantías de no repetición (Corte Constitucional del Ecuador, 2018), siendo obligación de la juzgadora o juzgador escoger el medio más idóneo para conseguir una verdadera reparación. Para efectos del tema de estudio, a pesar de que se recupere la libertad, el daño fue causado y resulta imposible volver las cosas a su estado anterior, en consecuencia, la medida de reparación más idónea y utilizada, suele ser la de compensación, que no es otra cosa que una indemnización de carácter económica, los daños indemnizables son el pecuniario, que a su vez se divide en daño emergente y lucro cesante y el daño no pecuniario, siendo este aquel que se causa a la moral o por el sufrimiento causado a la víctima (López, 2009).

Con respecto a la reparación económica, la Corte Interamericana de Derechos Humanos en el caso Garrido y Baigoirria vs. Argentina (1998) señaló "En lo que se 
refiere a violaciones al derecho a la vida, como en este caso, la reparación, dada la naturaleza del bien afectado, adquiere sobre todo la forma de una indemnización pecuniaria" (parr. 41). Aunque el derecho a la vida y el derecho a la libertad son a todas luces de distinta naturaleza, se aplica la misma línea de razonamiento en cuanto al tipo de reparación más conveniente. Pese a lo expuesto, la reparación de un derecho no siempre implicará una conducta positiva por parte del Estado, en algunas ocasiones la reparación se dará a través de una conducta negativa, es decir, absteniéndose de hacer algo (Moguel, 2010).

Como se puede apreciar, la Corte Constitucional del Ecuador, ha dado preponderante importancia a la reparación integral, llegando a establecer que si no se ha cumplido con la misma el proceso aún no concluye, incluso hace seguimiento de las sentencias, con el fin de verificar su cabal ejecución, es por esto que dentro de su jurisprudencia, ha desarrollado varios conceptos relacionados con la reparación integral, como son los constantes en la tabla 1 que se anexa.

\section{Tabla 1.}

Desarrollo constitucional de la reparación integral

\begin{tabular}{|c|c|c|c|c|}
\hline $\begin{array}{l}\text { Caso } \\
\text { N.- }\end{array}$ & Sentencia & $\begin{array}{c}\text { Corte } \\
\text { Constitucional }\end{array}$ & Año & $\begin{array}{l}\text { Concepto } \\
\text { desarrollado }\end{array}$ \\
\hline 1 & $\begin{array}{c}\text { 0004-09-SIS- } \\
\text { CC }\end{array}$ & $\begin{array}{l}\text { Corte Constitucional } \\
\text { para el período de } \\
\text { transición }\end{array}$ & 2009 & $\begin{array}{l}\text { Proceso } \\
\text { finaliza con la } \\
\text { reparación } \\
\text { integral }\end{array}$ \\
\hline 2 & $\begin{array}{c}004-13-S A N- \\
\text { CC }\end{array}$ & $\begin{array}{l}\text { Primera Corte } \\
\text { Constitucional }\end{array}$ & 2013 & $\begin{array}{l}\text { Reparación } \\
\text { integral es en } \\
\text { si misma un } \\
\text { derecho } \\
\text { constitucional }\end{array}$ \\
\hline 3 & $\begin{array}{c}\text { 024-14-SIS- } \\
\text { CC }\end{array}$ & $\begin{array}{l}\text { Primera Corte } \\
\text { Constitucional }\end{array}$ & 2014 & $\begin{array}{l}\text { Reparación } \\
\text { integral es } \\
\text { parte de la }\end{array}$ \\
\hline
\end{tabular}




\begin{tabular}{|c|c|c|c|}
\hline & & & $\begin{array}{l}\text { dignidad } \\
\text { humana }\end{array}$ \\
\hline $\begin{array}{c}4001-16-\text { SIS- } \\
\text { CC }\end{array}$ & $\begin{array}{l}\text { Segunda Corte } \\
\text { Constitucional }\end{array}$ & 2017 & $\begin{array}{c}\text { Dos esferas de } \\
\text { análisis, una } \\
\text { de } \\
\text { cumplimiento } \\
\text { formal y otra } \\
\text { de efectiva } \\
\text { ejecución }\end{array}$ \\
\hline
\end{tabular}

\section{El error judicial y la sentencia condenatoria revocada o reformada}

La Real Academia Española (2014), define el error como un concepto equivocado o juicio, así como también como una acción desacertada o equivocada. Siendo esto se considera al error judicial como la acción desacertada por parte de los operadores de justicia en la sustanciación de un proceso, lo cual a su vez conlleva a la vulneración de los derechos de alguna de las partes (Rangel, 2015), aunque no siempre será imputable a la juzgadora o juzgador, siendo procedente realizar un minucioso estudio de cada caso.

Con respecto al error judicial Tawil (1989) señala que, es el pronunciamiento de la juzgadora o juzgador que se genera en una desacertada apreciación de los hechos o del derecho, en cuyo caso es indistinta la existencia o no de culpa, siendo esto por tanto una violación de la obligación de emitir resoluciones motivadas, este tipo de errores pueden ocurrir en cualquier rama del Derecho. Es necesario diferenciar entre el error judicial y el error inexcusable (Código Orgánico de la Función Judicial, 2009), ya que si bien es cierto pueden presentar ciertas similitudes, el error inexcusable es una de las infracciones disciplinarias previstas para los servidores judiciales en el cumplimiento de sus funciones, mismo que ha sido objeto de varias críticas en Ecuador.

Por otro lado, el recurso de revisión, es sin duda alguna excepcional, por cuanto se interpone respecto de una sentencia ejecutoriada, imponiéndose por sobre el principio de cosa juzgada e incluso de seguridad jurídica, el mismo que surge cuando del 
proceso penal se presume que ha habido una sentencia condenatoria injusta, buscando sobre la base de nuevos elementos probatorios, de esta forma materializar el ideal de justicia que ha sido vulnerado, con la obtención de una sentencia acertada (Ostos, 2011).

Dicho esto, el inciso final del artículo 119 de la Constitución de la República del Ecuador, consagra la obligación de reparación a quién se haya visto afectado por una sentencia revocada o reformada, disposición Constitucional recogida en el artículo 32 del Código Orgánico de la Función Judicial, por tanto, de la lectura de las normas se entiende que en todo caso enmarcado en las normas precedentes se produjo un error o falla en el proceso penal, situación que ha derivado en una injusta sentencia; y, en un daño ilegítimo que merece ser reparado por parte de la administración, lo cual a su vez se enmarca en el ámbito de responsabilidad estatal dentro del espectro de responsabilidad del Estado.

En cuanto al debido proceso, como derecho humano y garantía judicial procesal, Rodríguez (2017) indica que es el derecho más vulnerado por los Estados, situación que a su vez culmina en la declaratoria de responsabilidad internacional por la Corte Interamericana de Derechos Humanos, órgano que se ha pronunciado señalado que el debido proceso debe ser observado y respetado en juicios de toda materia. Por tanto, se aprecia que el derecho al debido proceso es también considerado como un derecho humano, esto no ha sido solo manifestado por parte de tratadistas, sino incluso por la Convención Americana de Derechos Humanos, tal y como se puede encontrar en los artículos 7, 8, 9, 10, 24, 25 y 27 (Convención Americana sobre Derechos Humanos (Pacto de San José), 1969).

Sin perjuicio de lo expuesto, es necesario no perder de vista las particulares características del recurso de revisión, como son la posibilidad de presentarlo luego de ejecutoriada la sentencia y hacerlo sobre la base de nuevas pruebas, de igual manera hay que recordar que de revocarse una sentencia condenatoria, se lo ha hecho por ser injusta, causando por tanto un daño ilegítimo, hasta este punto no existe problema 
alguno, sin embargo, es aquí cuando se hace necesario determinar a quién es imputable la culpa por el daño, a la administración de justicia o al propio perjudicado, en este sentido, es necesario indicar que existen procesos judiciales en los que habiendo como antecedente una sentencia condenatoria revocada por un recurso de revisión no se ha imputado la culpa al Estado, teniendo como ejemplo el caso signado con el Nro. 01803-2017-00294, sustanciado por el Tribunal Distrital de lo Contencioso Administrativo No. 3 con sede en Cuenca.

El referido proceso, a su vez se origina en otro de naturaleza penal, de manera más específica uno de acción penal privada, que fue seguido contra un ciudadano que siendo citado no compareció, culminando con una sentencia condenatoria, por la que perdió su libertad. De forma posterior presenta recurso de revisión, instancia en la que aporta prueba que siempre estuvo a su disposición, siendo revocada la sentencia inicial. En razón de lo cual, plantea una demanda contra el Estado signada con el Nro. 018032017-0029, a fin de recibir una indemnización por el daño causado. Proceso en el que fue dictada sentencia, declarando sin lugar la demanda, por considerar el Tribunal que el proceso fue sustanciado en apego a la normativa legal pertinente, así como también que el daño causado no era imputable al Estado, sino a la propia falta de acción del perjudicado.

\section{METODOLOGÍA}

En la presente investigación se empleó el método analítico - sintético, con un enfoque descriptivo, para lo cual se ha recabado bibliografía consistente en libros, artículos de revistas científicas, sentencias, tesis de doctorado, considerando también normativa convencional, constitucional y legal, efectuando un análisis de cada uno de los elementos que integran la obligación estatal de resarcimiento en la figura de estudio, como son, el origen y alcance de la responsabilidad estatal, análisis de los factores integrantes del daño antijurídico, obligación de reparación con la forma de efectuarla y el error judicial haciendo énfasis en la sentencia condenatoria reformada o revocada, 
con la finalidad de establecer cual deber ser el real alcance de la obligación de reparación (González, Erazo, Ormaza y Narváez, 2020).

\section{APORTES GENERADOS}

El principio de responsabilidad de los Estados respecto de sus actos, resulta fundamental dentro del actual paradigma constitucional, en el que se ha pasado de un Estado legalista o de Derecho, a un Estado de justicia y de derechos, esta diferencia que a priori parecería ser solo dialéctica, implica una profunda diferencia entre uno y otro modelo de gobierno, ya que actualmente el ser humano y el respeto a los derechos es el centro, el objeto y la finalidad misma del Estado ecuatoriano. Siendo esto así, uno de aquellos derechos que deben ser siempre respetados, es el de acceso a la justicia, el mismo que no se puede entender separado del de tutela judicial efectiva y debido proceso, contexto dentro del cual, es derecho de todos quienes acuden a la administración de justicia, recibir una respuesta que de una correcta solución a su problema.

Ante esto se considera saludable el reconocimiento que en la Constitución del año 2008, se hace respecto de la obligación de reparación del Estado, por los daños causados a las personas, haciendo particular énfasis en lo atinente a la administración de justicia; lo cual implica que las juezas y los jueces también son responsables por sus actos, situación que se traduce en una mejor calidad en cuanto a la sustanciación y resolución de los conflictos judiciales, sin embargo, es necesario ser cauteloso en cuanto al alcance de esta responsabilidad, puesto que no establecer un adecuado marco legal, puede implicar una situación de injusticia hacia la juzgadora o juzgador, así como también un resarcimiento no pertinente.

Si bien es cierto no se establecen parámetros para determinar cuándo procede la reparación por una sentencia condenatoria revocada o reformada, es necesario efectuar un análisis integral de la doctrina y del derecho, con este antecedente se ha determinado que un elemento fundamental para proceder con una reparación es la 
existencia de un daño, pero no cualquiera sino uno que pueda en efecto ser calificado como ilegítimo, hay que recordar que la mayoría de las sentencias imponen alguna carga u obligación sobre una de las partes, constituyéndose esta en un daño, mas se trata de uno lícito. Por lo que será necesario estar ante un daño ilícito.

Sin duda, esto no es suficiente ya que se puede estar ante un escenario en que haya una sentencia con la que se condene a una persona inocente, ocasionándose por tanto un daño ilícito o injusto. Hay que recordar que el artículo 658 del Código Orgánico Integral Penal establece que para la procedencia de la revisión debe haber nuevas pruebas que evidencien el error de hecho de la sentencia, la presentación de estas nuevas pruebas recién en este momento y no durante la sustanciación del proceso penal, por lógica implica que o no se tuvo conocimiento de las mismas o no hubo acceso, no se puede entender que alguien en un proceso seguido en su contra, deliberadamente decida ocultar pruebas con las que pueda ratificar su estado de inocencia, prefiriendo ser privado de su libertad. Pese a lo expuesto, como se dejó anotado anteriormente, casos como el señalado se han dado en la práctica.

Luego del análisis efectuado en el presente trabajo, a fin de determinar si en verdad se está ante un caso de sentencia condenatoria revocada o reformada que merezca una reparación, debería efectuarse un minucioso estudio de cada caso particular en el que en primer lugar se debe verificar si se ha dado estricta observancia al debido proceso, de igual manera se debe verificar si la sentencia ha sido motivada conforme a los parámetros establecidos para el efecto por la Corte Constitucional, estos dos aspectos deberían ser objeto de un primer análisis. De manera posterior se debería observar el origen de la nueva prueba aportada con el fin de determinar si es que en efecto no ha sido posible obtenerla de manera previa o si de manera deliberada fue ocultada, para obtener un beneficio económico, lo cual significa que de haber un daño este es imputable al mismo perjudicado. De lo expuesto podemos concluir que en la responsabilidad extracontractual del Estado, hay tres elementos, daño lícito o ilícito, imputabilidad a alguien distinto del afectado y reparación. 
En razón de que la disposición constitucional es demasiado abierta en cuanto a considerar como culpable siempre a la administración de justicia, es pertinente, desarrollar normativa que permita cumplir con este mandato constitucional de una manera más eficaz. No se puede considerar esto restrictivo de derechos, sino por el contrario se lograría una mejor determinación de la culpa en este tipo de casos, ya que lo otro implica incluso llegar a nuevas situaciones de injusticia, ya que de la mano del resarcimiento económico, viene el derecho de repetición, que de forma eventual podría recaer sobre una juzgadora o juzgador que actuó de manera correcta en la sustanciación del proceso.

\section{REFERENCIA CONSULTADAS}

1. Asamblea Nacional del Ecuador. (03 de marzo de 2009). Codigo Orgánico de la Función Judicial.

2. Código Orgánico de la Función Judicial. (2009).

3. Convención Americana sobre Derechos Humanos (Pacto de San José). (22 de noviembre de 1969). Convención Americana sobre Derechos Humanos (Pacto de San José). Convención Americana sobre Derechos Humanos (Pacto de San José). San José, Costa Rica.

4. Corte Constitucional del Ecuador. (2018). Reparación IntegralAnálisis a partir de la jurisprudencia de la Corte Constitucional del Ecuador. Quito.

5. Corte Suprema de Justicia, 228-2001 (Corte Suprema de Justicia 29 de julio de 2002).

6. Delpiazzo, C. (2009). La responsabilidad ante la huída del derecho administrativo. A\&C Revista de Direito Administrativo \& Constitucional, 14.

7. Fenech, M. (1947). Instituciones de Derecho procesal penal. Barcelona: Librería Bosch.

8. Fundación Regional de Asesoría en Derechos Humanos INREDH; Centro Ecuatoriano para la Promoción y Acción de la Mujer CEPAM. (2000). El derecho a la reparación en el proesamiento penal. Quito: Comunicaciones INREDH.

9. Garantías Judiciales en Estados de Emergencia (Corte Interamericana de Derechos Humanos 06 de octubre de 1987). 
10. Garrido y Baigoirria vs Argentina, Serie C No. 26, Serie C No. 39 (Corte Interamerica de Derechos Humanos 27 de agosto de 1998).

11. González Castillo, S. L., Erazo Álvarez, J. C., Ormaza Ávila, D. A., \& Narváez Zurita, C. I. (2020). La Desnaturalización de los Estados de Excepción. Iustitia Socialis, 365.

12. Gordillo, A. (2013). Tratado de derecho administrativo y obras selectas. Buenos Aires: Argentina.

13. Gordillo, A. (2017). Tratado de Derecho Administrativo y obras selectas. Buenos Aires: Fundación de Derecho Administrativo.

14. Granda Torres, G., \& Herrera Abrahan, C. (2019). Análisis de los tipos penales y su importancia para determinar responsabilidad penal. IUSTITIA SOCIALIS, 4(7), 220-232. doi:http://dx.doi.org/10.35381/racji.v4i7.443

15. Hernandez, M. (2017). El Estado como legislador dañoso y su responsabilidad reparadora. Guayaquil, Guayas, Ecuador: Murillo Editores.

16. Hernández, M. (2017). El Estado como legislador dañoso y su responsabilidad reparadora. Guayaquil, Guayas, Ecuador: Murillo Editores.

17. Jiménez, W. (2013). Orígen y Evolución de las teorías sobre responsabilidad Estatal. Dialogos de Saberes, 68.

18. López, C. (2009). Aproximación a un estándar de reparación integral en procesos colectivos de violación a los derechoshumanos. Jurisprudencia de la Corte Interamericana de Derechos Humanos. Revista Estudios Socio-Jurídicos.

19. Mir, L., y Dalcero, I. (2007). ¿Una diarquía medieval? El combate ideológio entre dos espadas. San Miguel de Tucumán: XI Jornadas Interescuelas/Departamentos de Historia. Facultad de Filosofía y Letras. Universidad de Tucumán.

20. Mogrovejo, D. (2009). La responsabilidad estatal en la Constitución del Ecuador de 2008. Foro Revista de Derecho, 73.

21. Moguel, M. (2010). La responsabilidad y el deber de reparar por violaciones a los derechos humanos. Dfensor.

22. Moreno, J. (2016). La responsabilidad extracontractual del Estado en el Ecuador: las limitaciones en el marco jurídico. Revista luris.

23. Nanclares, J., y Gómez, A. (2017). La reparación: una aproximación a su historia, presente y prospectivas. Civilizar. 
24. Naveira, M. (2004). El resarcimiento del daño en la responsabilidad civil extracontractual (tesis de doctorado. Universidade da Coruña. Departamento de Dereito Privado, La Coruña.

25. Ostos, M. (2011). Manual de derecho procesal penal. Sevilla: Astigi.

26. Oyarte, R. (2019). Derecho Constitucional. Quito: Corporación de Estudios y Publicaciones.

27. Ramallo, J. (1982). Derecho constitucional y derecho financiero. Cuadernos de la facultad de derecho, 50-51.

28. Rangel, X. (2015). La indemnización por error judicial: El derecho olvidado al imputado dentro de la reforma constitucional en materia de seguridad y justicia de 2008. El Colegio de San Luis, 207.

29. Rodríguez, V. (2017). El debido proceso legal y la Convención Americana sobre Derechos Humanos.

30. Romero, J. (2015). La primera fase histórica del servicio público. Revista de Ciencias Jurídicas, 138.

31. Sentencia C-333/96 (Corte Constitucional de la República de Colombia 01 de agosto de 1996).

32. Sentencia Nro. 227-12-SEP-CC (Corte Constitucional del Ecuador 21 de junio de 2012).

33. Sentencia Nro 004-13-SAN-CC (Corte Constitucional del Ecuador 13 de junio de 2013).

34. C-314/14 (Corte Constitucional de la República de Colombia 4 de junio de 2014).

35. Sentencia C-341/14 (Corte Constitucional de la República de Colombia 04 de junio de 2014).

36. 01803-2017-00294 (Taibunal Distrital de lo Contencioso Administrativo nro. 3 con sede en Cuenca 27 de abril de 2018).

37. Scognamiglio, R. (2001). Responsabilidad contractual y extracontractual. Ius et veritas, 54.

38. Tawil, G. (1989). La Responsabilidad del Estado y de los Magistrados y Funcionarios Judiciales por el Mal Funcionamiento de la Administración de Justicia. Buenos Aires: Ediciones Depalma. 
39. Velásquez, F., y Gutiérrez, C. (2011). La diferencia entre dolo eventual y la culpa consciente en la reciente jurisprudencia. Cuadernos de derecho penal, 153-156.

(C)2020 por los autores. Este artículo es de acceso abierto y distribuido según los términos y condiciones de la licencia Creative Commons Atribución-NoComercial-Compartirlgual 4.0 Internacional (CC BY-NC-SA 4.0) (https://creativecommons.org/licenses/by-nc-sa/4.0/). 